\title{
A REVIEW OF THE AGYRTES (SILPHIDAE) OF NORTH AMERICA*
}

\author{
By Stewart B. Peck \\ Department of Biology, Carleton University, \\ Ottawa, Ontario, Canada
}

Dr. John Lawrence and Dr. Roy Crowson pointed out to me that the type specimen of Lendomus politus Casey (placed in Mycetophagidae by Casey) seemed to be a silphid in the genus Agyrtes. This led me to study the Casey type and to review the species of Agyrtes of North America as the first part in a projected series of reviews of the silphid genera of North America.

The genus Agyrtes is Holarctic. Seven species are known and a key to them is given by Hlisnikovsky (1964). Of these, two species occur in and are limited to North America. The habits of the North American species are unknown, but the European species occur in forests under bark, in moss, and at rotting mushrooms.

\section{Agyrtes longulus (LeConte)}

Figures I, 2, 8, 9, IO.

Necrophilus longulus LeConte, 1859: 282. Lectotype here designated as female in MCZ, LeConte colln. (no. 3148), bearing gold disc, seen. Type locality: Table Mountain, below San Francisco, California, by original designation.

Agyrtcs longulus (LeC.). Horn, 1880:246. Hatch, 1957:8.

Lendomus politus Casey, 1924: 184. New Synonym. Holotype male in USNM, Casey colln. (no. 37497), seen. Type locality; Anticosti Island, Quebec, Canada. No other type data.

Diagnosis. Antennal club composed of four segments, first three of club with rings of dense pubescense on inside apical margin, third antennal segment appreciably longer than the second. Prothorax conspicuously wider than long, less narrowed towards the front, posterior angles distinct. Aedeagus in side view with pronounced bend (fig. IO), paramere an elongated spatula (fig. 9).

Distribution. The species ranges from southern California northwards through the coastal mountains to British Columbia and southern Alaska, and inland to Idaho. In addition to the type I have seen the following material:

*Manuscript received by the editor December 17, 1974. 


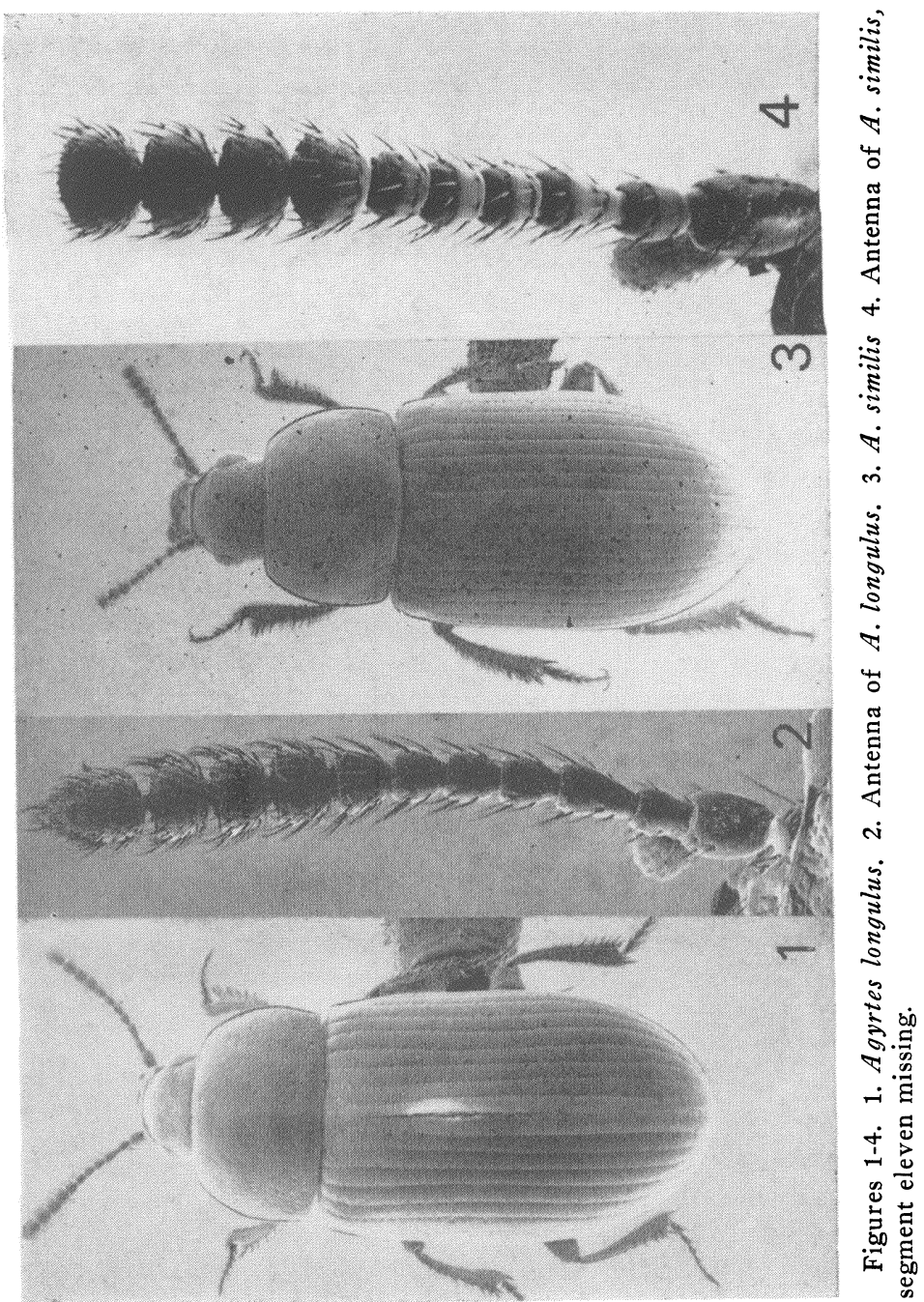


Canada. British Columbia. Creston. I5-xi-3I, G. Stace Smith (abbreviated subsequently as GSS), I (CNCI); 29-ii-32, GSS, I (CAS) : I I-xi-32, GSS, I under wood at 2000' (CAS); Io-xi-33, GSS, I on ground, 2000' (MCZ) ; 29-xi-33, GSS, I in flood debris at $1750^{\prime}(\mathrm{MCZ})$; $\mathrm{I}-\mathrm{xi}-45, \mathrm{GSS}, \mathrm{I}(\mathrm{MCZ})$; $2 \mathrm{I}-\mathrm{xi}-5 \mathrm{O}, \mathrm{GSS}, 3$ on snow (CAS); 24-xi-5o, GSS, I on snow (CAS) ; 27-xi-5o, GSS, 23 on snow (CAS); I0-xii-50, GSS, I on snow (CAS); 1952, GSS, 4 (FMNH) ; 26-iii-56, GSS, I (CNCI) ; I8-iv-56, GSS, I (CNCI). Queen Charlotte Islands. Massett, io (USNM); no locality, 5 (CAS, CNCI, USNM). Salmon Arm, I I-iv-28, HB Leech, I (CNCI) ; I 2-iv-35, H. Leech, I (MCZ); 2I-xii-35, SH $\& \mathrm{O}$ Leech, I on snow (CAS). Terrace, viii-1927, ME Hippsley, I (MCZ) ; ME Clark, no other data, I (MCZ). Vancouver, 28-i-3I, HB Leech, 2 (CAS, CNCI) ; 26-iii-33, HB Leech, I flying, (Fall colln. MCZ); no other data, I (LeConte colln., MCZ).

United States. Alaska. Sitka, 5 (USNM). California, Alameda County, Berkeley, 22-ii-2O, JO Martin, 3 (CAS). Glenn County, Elk Creek, I7-iv-I3, R Hopping, I on Pinus ponderosa (CAS). Marin County, Mill Valley, 22-ii-26, Van Duzee, I (CAS) ; 8-x-5 I, RE Leech, I at light (CAS); 9-i-56, HB Leech, I (CAS). Mt. Tamalpais, 23-v-09, Van Dyke, I (CAS). Taylorville, 28-xii-r9, JO Martin, I (CAS). Monterrey County, Carmel, 27-xii-I4, I (CAS). Plumas County, 2 (USNM). San Francisco County, San Francisco, 8-i-i I, Van Dyke, I (CAS). Santa Clara County, no other data, I (CAS). Sonoma County, Eldridge, I 7-xii-Io, Van Dyke, 2 (CAS) ; southern Sonoma County, 9-xii-ro, Van Dyke, 2 (CAS) ; I I-xii-IO, I (CAS) ; I4-xii-ı,, Van Dyke, 3 (CAS). 29i-I I, Van Dyke, 3 (CAS). Oregon. No other data, I (USNM). Clackamas County, Colton, iv-35, ES Ross, I (CAS); Yamhill County, 2-iii-34, ES Ross, I (CAS). Washington. King County, Seattle, 3-v-1 4, 2 (Fall colln., MCZ) ; 28-ii-98, I (CAS); no other data, 3 (CAS). Thurston County, Olympia, no other data, I (Fall colln., MCZ).

Hatch (1957) also mentions that the species occurs in northern Idaho.

Biology. Virtually nothing is known of the habits of the species or of its life cycle. The seasonality data show that it is most active in the winter months. The species has been taken most often on snow but also in flood debris, and under chips of live oak. It is presumably associated with forested habitats.

Notes on synonymy. The type of Lendomus politus Casey was examined and dissected. It was found to be identical, within reason- 
able limits of variation in the shape of the aedeagus, with Agyrtes longulus. Since a number of beetles in eastern Canada have been introduced from Europe (Lindroth, I957) there was the possibility that the Agyrtes of Casey might be a species introduced from Europe. It was compared with the European $A$. castaneus (F.) and the aedeagus drawings of Hlisnikovsky (1964) and was found to be distinctly different.

Since Casey's specimen is the only Agyrtes known from eastern North America, I think that an error was made in the labeling of Casey's Agyrtes, and we may continue to believe that the genus Agyrtes and the species $A$. longulus occur only in the coastal and interior mountains of western North America.

\section{Agyrtes similis Fall \\ Figures 3, 4, 5, 6, 7 .}

Agyrtes similis Fall, 1937; 29. Holotype male in MCZ, Fall colln. (no. 24015), seen. Type locality: Pasadena, California.

Diagnosis. Antennal club composed of five segments, first four of club with rings of dense pubescense on inside apical margins, third antennal segment only a little longer than the second. Prothorax wider than long but more elongate and more gradually narrowed toward the front, posterior angles rounded. Aedeagus in side view relatively straight (fig. 7), paramere a rounded spatula (fig. 6).
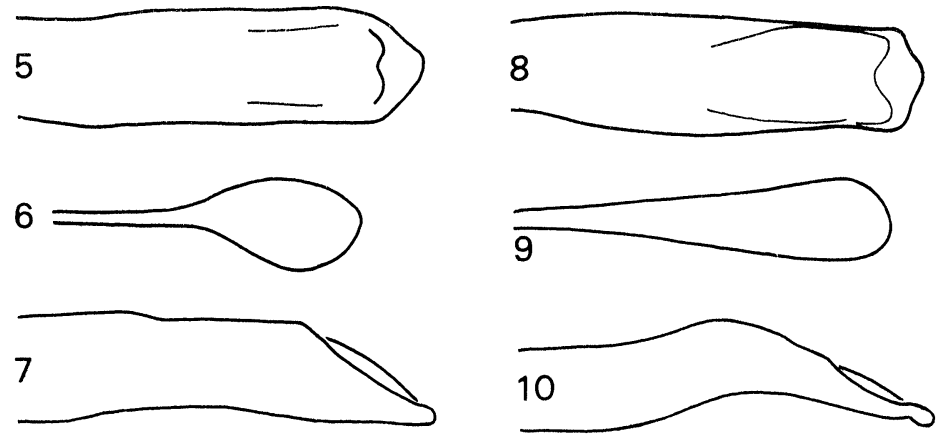

Figures 5-10. 5. A. similis aedeagus, dorsum, Pasadena, California. 6. A. similis paramere, setae omitted. 7. A. similis aedeagus, lateral view. 8. A. longulus aedeagus, dorsum, Mill Valley, Marin Co., California. 9. $A$. longulus paramere, setae omitted. 10. A. longulus aedeagus, lateral view. 
Distribution. The species is known only from the coastal ranges of central and southern California. In addition to the type I have seen the following specimens:

California. Alameda County, Alameda, I-iv-9o, I (Koebele colln., CAS). Los Angeles County. Pasadena, Jan., I; Feb., I ; Mar., I ; (Fenyes Colln., CAS). Pomona, mountains, I5-xi-96, I (Fall colln., MCZ). "Cala," no other data, 2 (Horn colln. in MCZ).

Biology. Nothing is known of the habits or life cycle of this beetle. The collection records show that it is active only in the winter months. It is presumably associated with forested habitats.

Notes. There is a remarkable similarity in the dorsal view of the aedeagus and of the paramere of Agyrtes bicolor Lap. of central Europe (as illustrated by Hlisnikovsky, 1964) and of $A$. similis, but other characters in the key of Hlisnikovsky seem to separate the species. The aedeagus of $A$. bicolor in side view is not illustrated. I have not studied material of $A$. bicolor, although I have seen the Hlisnikovsky collection in Prague.

\section{Acknowledgements}

I wish to thank the following for having made available for study material in the collections under their care: M. J. Campbell, Canadian National Collection of Insects, Ottawa (CNCI) ; H. Dybas, Field Museum of Natural History, Chicago (FMNH); J. M. Kingsolver, U. S. National Museum, Systematic Entomology Laboratory (USNM). J. F. Lawrence, Museum Comparative Zoology, Harvard University (MCZ) ; H. B. Leech, California Academy of Sciences, San Francisco (CAS). H. F. Howden and J. F. Lawrence are thanked for reviewing the manuscript. L. E. C. Ling of Carleton University took the SEM photographs.

\section{Literature Cited}

CASEy, T. L.

1924. Memoirs on the Coleoptera, XI, $346 \mathrm{pp}$.

FALL, H. C.

1937. Miscellaneous notes and descriptions (Coleoptera). Can. Ent., 69: 29.

НАTCH, M. H.

1957. The beetles of the pacific northwest. Part II: Staphyliniformia. Seattle: Univ. Wash. Pub. Biol., 16, 384 pp.

HLISNIKovsky, J.

1964. Zur Kenntnis der Gatung Agyrtes Lap. (Coleoptera, Silphidae, Agyrtini). Reichenbachia, 2: 275-278. 
HORN, G. H.

1880. Synopsis of the Silphidae of the United States, Trans. Amer. Ent. Soc., $8: 219-322$.

\section{LECONTE, J. L.}

1859. Additions to the Coleopterous fauna of northern California and Oregon. Proc. Acad. Nat. Sci. Philadelphia, 281-293.

LINDROTH, C. H.

1957. The faunal connections between Europe and North America. New York, Wiley and Sons, 344 pp. 

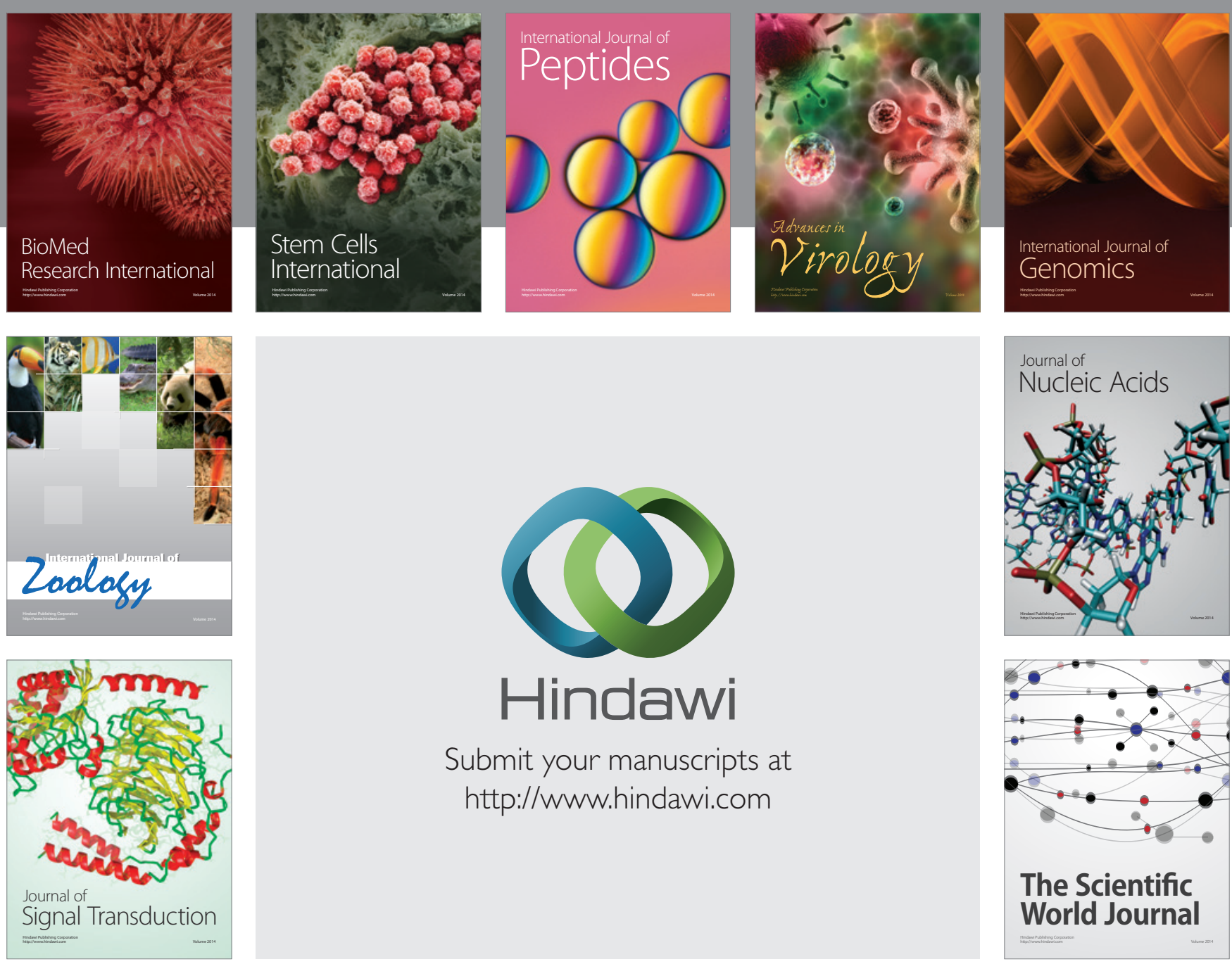

Submit your manuscripts at

http://www.hindawi.com
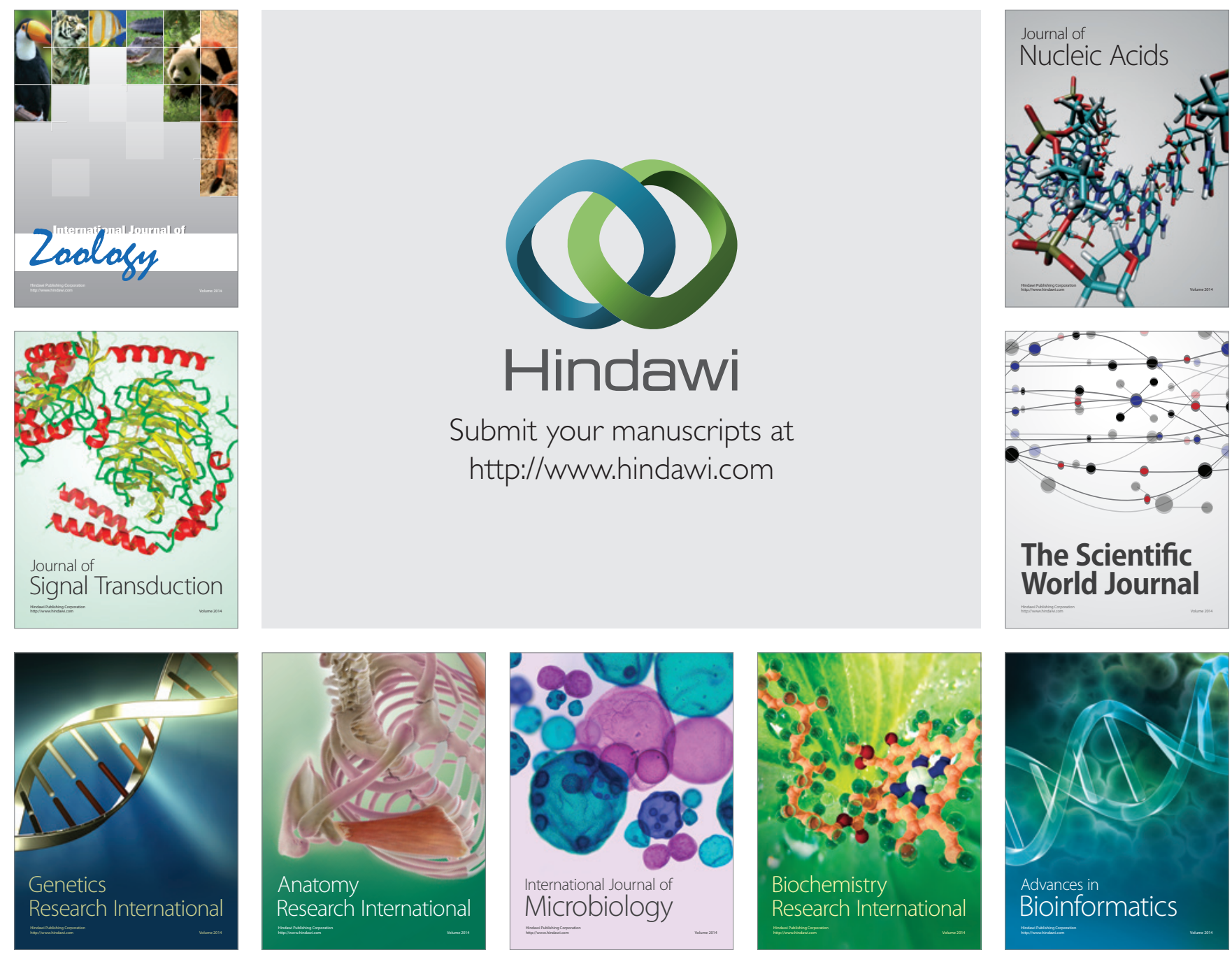

The Scientific World Journal
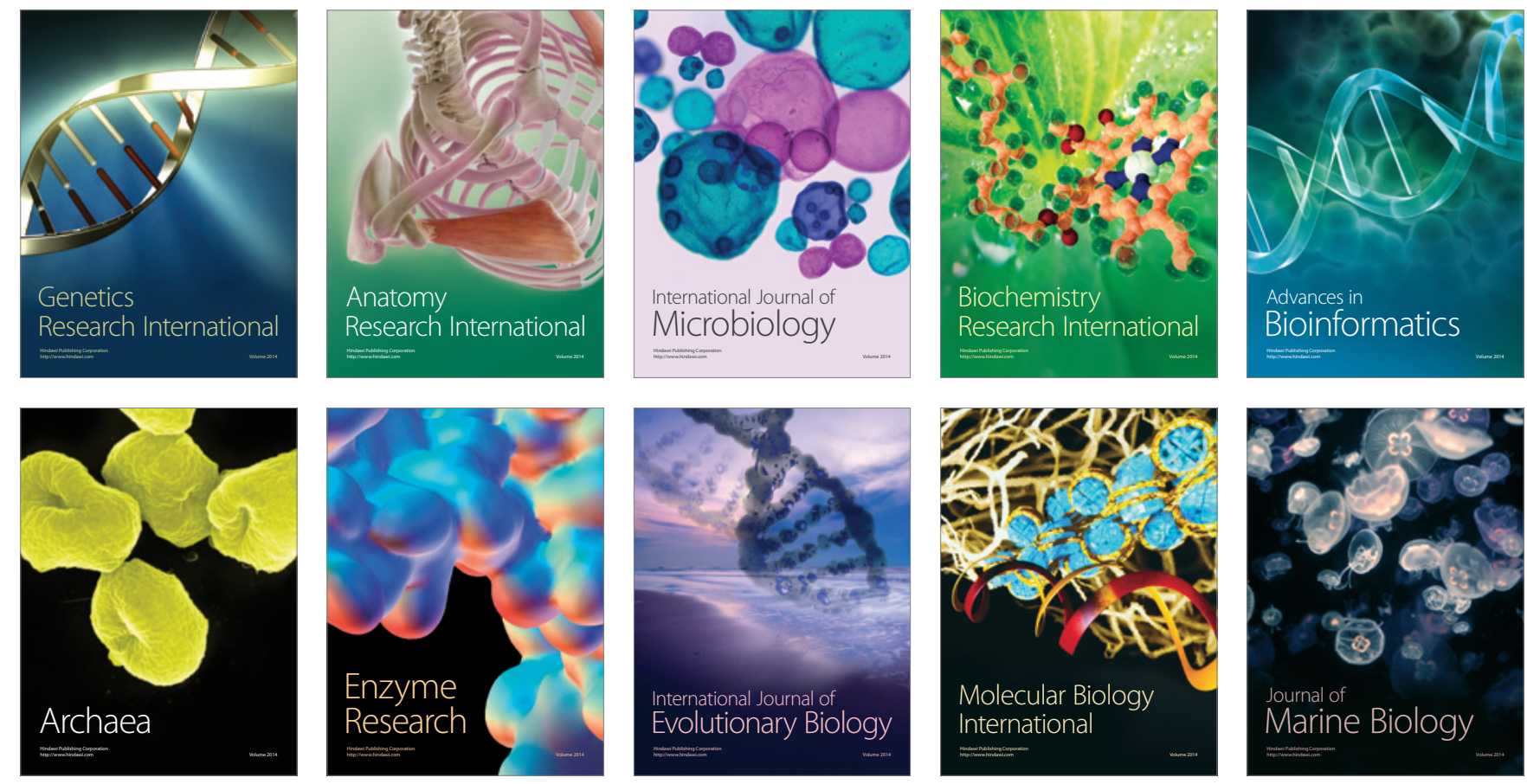